\title{
Effect of a Cooling Unit on High-speed Motorized Spindle Temperature With a Scaling Factor
}

Dexing Zheng ( $\sim$ zdxeducn@163.com )

Nanjing University of Aeronautics and Astronautics

\section{Weifang Chen}

Nanjing University of Aeronautics and Astronautics

\section{Research Article}

Keywords: motorized spindle, coolant system, structural factor

Posted Date: August 24th, 2021

DOl: https://doi.org/10.21203/rs.3.rs-831733/v1

License: (9) This work is licensed under a Creative Commons Attribution 4.0 International License. Read Full License 


\title{
Effect of a cooling unit on high-speed motorized spindle temperature with a scaling factor
}

\author{
Zheng De-xing ${ }^{1,2 *}$, Chen Weifang ${ }^{1}$ \\ ${ }^{1}$ College of Mechanical and Electrical Engineering, Nanjing University of Aeronautics and \\ Astronautics, 210016 Nanjing, P.R. China; \\ ${ }^{2}$ College of Mechanical Engineering, Jinggangshan University, 343009 Ji'an, P.R. China; \\ *Corresponding author: Zheng De-xing, E-mail: zdxeducn@163.com
}

\begin{abstract}
Forced cooling, as an efficient way of heat dissipation, significantly affects the spindle temperature. Although a full cooling passage was factored into the finite element analyses by some scholars, often only the model for the front or rear half of a spindle is need for the purpose of the thermal evaluation simplification and data overhead reduction in engineering applications. So far, how the coolant passage affects the heat dissipation of the front or rear half of a spindle has not been well characterized. This paper devotes to constructing a scaling factor to represent the coolant unit effect on the thermal growth of spindles. The experiments about the effect of coolant units on spindle temperature were first implemented, and then the qualitative conclusions were got with various coolant parameter settings. To further quantify these influences, the regressive analysis was carried out. As a result, the peak temperature area was found and the scaling factors were proposed to describe the effect of the cooling system on the front or rear half of spindle temperature. In this process, the thermal equivalent convection for coolant passage was modeled based on the thermal resistance theory. In the meantime, we planned a novel thermal network of a motored spindle for contrast and validation, in which the cooling mechanism was integrated, and the structural constraints were considered by the aid of the proposed scaling factors. The result is indicative of a better agreement with real values when employing the proposed model.
\end{abstract}

Key words: motorized spindle, coolant system, structural factor

\section{Introduction}

Many studies demonstrate that the performance of a high-speed spindle is closely related to its thermal growth. To accurately assess the thermal behaviors of spindles, the heat generation and dissipation were investigated successively [1-2]. Bearing and motor are the two key parts influencing the performance of a high-speed motorized spindle, and they are also the main heat sources to determine the thermal behavoiurs of spindles. To dissipate their heating for lower operation temperature and then more ideal working accuracy has been fully valued by researchers. Many numerical models by finite element theory, lots of physical equations based on heat transfer mechanism and various empirical formulas with test data were constructed to analyze quantitatively the corresponding heat exchange [3-5]. Numerous optimization algorithms, meanwhile, were also proposed to further explore the the heat sources, thermal deformation and temperature profile of spindles [6].

In these current studies, however, an enormous amount of research effort only considered the power loss of bearings, the heat conduction between bearings and surrounding parts and the convection effect between bearings and coolant / lubricant as well, and yet how the heat given out by motor armatures is transmitted has not been thoroughly addressed thus far. In this area some scholars also integrated the motor heating influence into the spindle temperature field, for example Chen et al. [7] constructed a power flow model of built-in motor for exploring the temperature field variation and thermal error of a motorized spindle unit, while the contact statuses between parts 
were ignored; Zhang et al. [8] established a finite element model for motorized spindles, in which the motor is only a thermal source. Lately, Meng et al. [9] took various fractal parameters into a mathematical model to describe the thermal contact conduction between rotor and stator, but the detailed thermal transmission between rotor/stator and the objects around them was not fully considered. Well, to sum up, the detailed heat transfer of motor armatures was often dismissed.

Further, cooling, as an efficient way to lower the temperature, is usually needed in two locations: bearings and motor for a high-speed motorized spindle [10]. The cooling for bearings is often accompanied by lubrication, whose corresponding impact on spindle temperature has been investigated by many scholars, such as Michael et al. [11]. In contrast, the energy loss of motor armatures is much bigger than bearings and therefore is regarded as the most important thermal source of a spindle. So, a separate coolant system, for the purpose of dissipating the motor heating fast, is very essential. Here are some passive/active ways to cool electric motors, for example the forced/free air cooling, the liquid cooling by oil/water, the loop thermosyphon, the evaporative cooling using liquid boiling, the additional circuit for enhanced heat transfer, etc. [10,12-13], among which the air cooling is more suitable for small power motors and the evaporative cooling is mainly employed in super high-power applications. From the complexity of cooling units, the forced air and liquid cooling are more practical than other cooling approaches in engineering. After further comparison, the conventional forced convection by oil or water is more efficient and as a result is most popular in various rotation spindles, especially high-speed motorized spindles.

Firstly, Biesack and Loomis [14] set the helical passage for a motorized spindle housing. With the aid of a separate channel, Shigenori and Narashino [15] later separated the cooling from bearing lubrication. After this, Xia et al. [16] designed the fractal tree-like model and applied it into the cooling sleeve of spindle; Kang et al. [17] proposed a novel shaft core cooling approach to further reduce the spindle temperature, and Liu et al. [18] constructed a thermal simulation speculation-based active coolant control strategy.

Various forced cooling structures by water/oil, as stated above, were designed by scholars successively. However, there is still a long way to go till these new cooling schemes can be used in engineering. To improving the existing designs is another more practical road to make heat exchange better in comparison. In this connection, Grama et al. [19] constructed a control strategy (Cooler Trigger Model) with higher cooling effectiveness; Mori et al. [20] developed an on-off control way to reduce the power loss of a coolant unit with a hot gas bypass. Again, Chien and Jang [21] integrated the helical cooling passageway into a 3-D fluid model of motorized spindle, and next both numerical and experimental studies of spindle temperature distribution were implemented; Zhu et al. [22] carried out the numerical simulation and experiments to discuss and then validate the effect of shaft core cooling. However, these above finite element models are with excessive data overhead, and thus are more usually adopted in scientific researches. By contrast, the concise heat transfer models based on thermal network method have a much lower data overhead and show more specific heat exchange between parts, and therefore are more practical in engineering applications [23]. Furthermore, often scholars only modeled the first half of the spindle to simplify the thermal evaluation model further. Yet it is a fact of life is that the cooling units are either not integrated into the presented thermal grid models [5,24], or they are taken for granted by researchers that $50 \%$ of each coolant passage is applied to the heat dissipation of the front/rear end of a spindle [25]. Obviously, how the substructures outside a coolant passage affect the heat dissipation of cooling system was ignored.

Although a lot of work has been done by researches, as described above, the thermal performances of cooling systems have not been thorough thus far. Some scholars investigated how 
the cooling parameters affects the temperature, and the cooling units were also integrated as a whole into the finite element analyses to explored the spindle temperature by some others, but how the coolant passage affects the heat dissipation of the front and rear half of a spindle separately was seldom mentioned. Consequently, there is still a lack of an accurate, simple and suitable model to evaluate the influence of cooling units on spindle temperature so far.

In this paper, the heat convection in coolant passage was explored experimentally. Through the regressive analysis on test data, the scaling factor was introduced to represent the roles of a coolant passage in the thermal estimation.

\section{Experimental study about coolant system effect on motorized spindle temperature}

\subsection{Experiment setup}

To investigate the role of coolant systems in cooling motorized spindles, the test project to detect the temperature of motorized spindle (1), as shown in Fig.1, was created to analyze the effect of various cooling settings on heat exchange, in which the initial axial load was $400 \mathrm{~N}$. In experimenting, we changed the coolant flux and working temperature by adjusting oil cooler (7), and the ambient temperature, shaft speed and oil/air flow rate for lubrication were regulated through the air conditioner, variable-frequency drive (6) and oil-air lubrication device (4) respectively. In order to monitor the spindle temperature change under different cooling parameters, 8 thermal resistance temperature sensors (12-19) were evenly placed on the outer surface of spindle cooling sleeve and 2 built-in thermistors (10-11) on the outer rings of front and rear spindle bearings as well. At the same time, the thermal resistances (8) and (9) are used to measure the temperature of discharged oil-air and coolant separately. It should be noted that the spindle in the test is Setco231A240, whose supporting bearing is 7009AC from SKF. The double helical design is employed in the cooling system of spindle, and the corresponding cooling media is the spindle oil No.5.

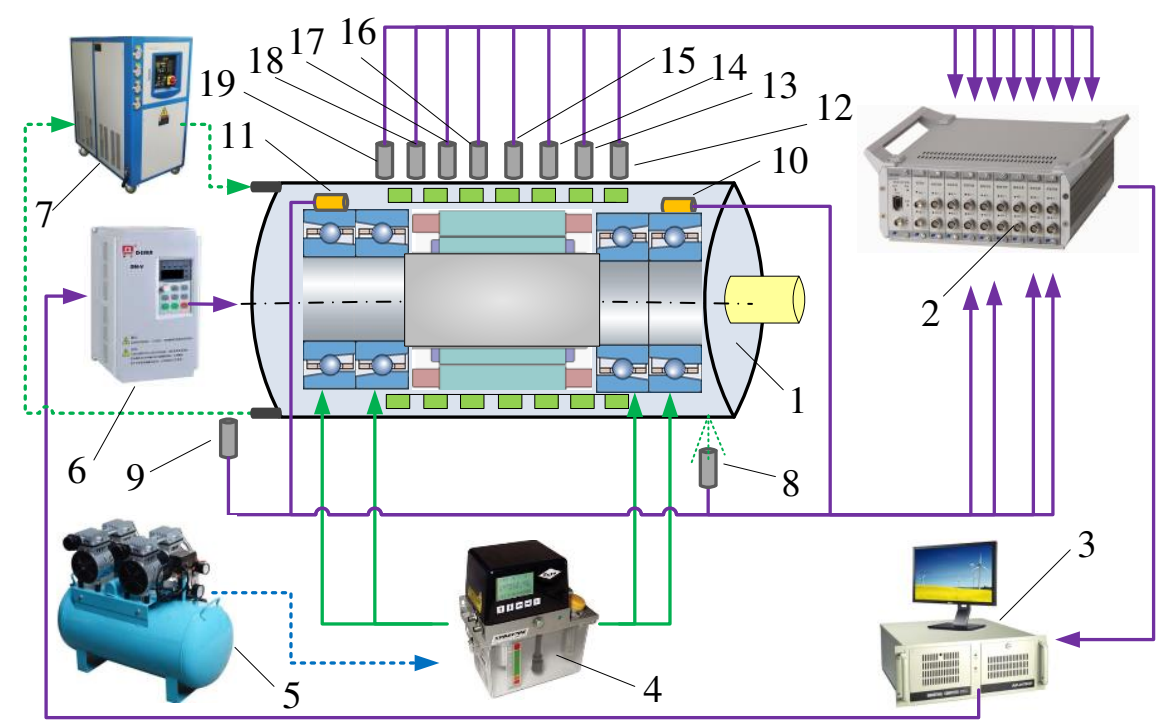

Fig.1. Experimental scheme for spindle temperature.

\subsection{Experiment results}

In this test project, the mean value of temperature was employed to evaluate the impact of cooling unit on the thermal characteristics of a motored spindle. Figs.2 3 depict the temperature difference on the spindle housing surface from front bearing to rear bearing when the coolant flow rate was changed from $3 \mathrm{~L} / \mathrm{min}$ to $4.5 \mathrm{~L} / \mathrm{min}$. The other test conditions are 


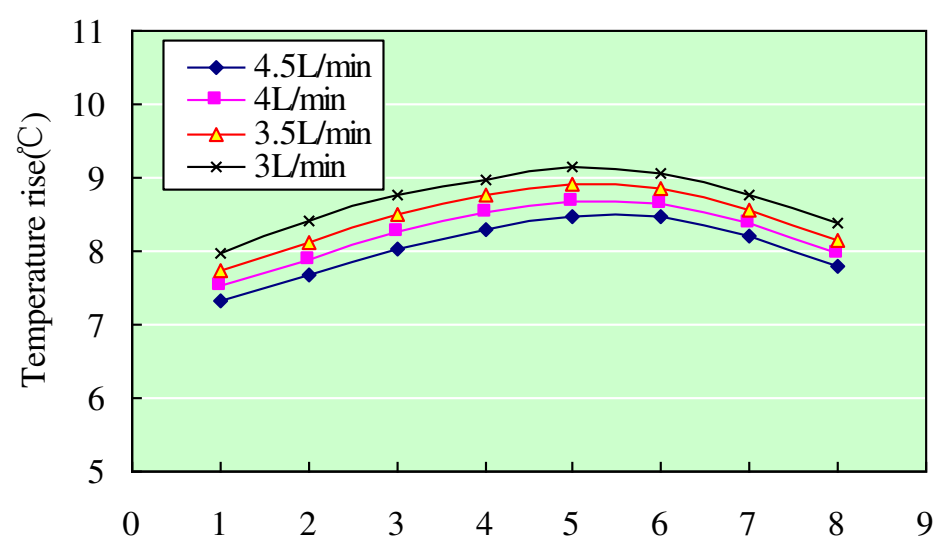

Fig.2. Temperature difference on cooling sleeve surface for various coolant flow rate at 8000rpm.

1) The ambient air is $22^{\circ} \mathrm{C}$, and the oil cooler operates at $20^{\circ} \mathrm{C}$.

2) The flow rate of lubricating oil is $0.6 \mathrm{ml} / \mathrm{h}$, and it's viscosity is $22 \mathrm{~mm}^{2} / \mathrm{s}$.

3) The air flow flux is regulated by adjusting the air supply pressure, it's value is $2.5 \mathrm{e}-3 \mathrm{~m}^{3} / \mathrm{s}$. The evident results are as below.

1) It's obvious the temperature distribution is not uniform along axial direction. The maximum error is nearly $0.8^{\circ} \mathrm{C}$ when the spindle operates at $12000 \mathrm{rpm}$, and this deviation is less than $1.2^{\circ} \mathrm{C}$ at $8000 \mathrm{rpm}$.

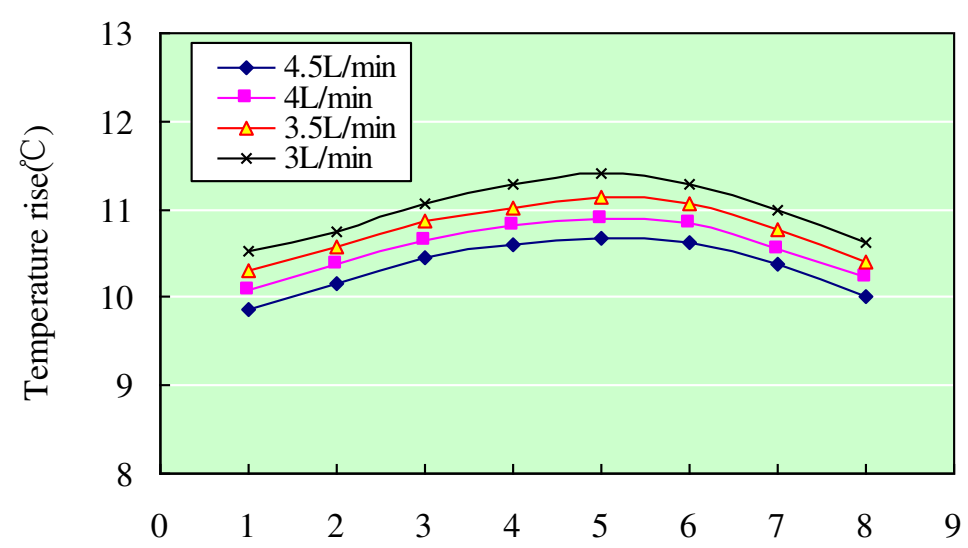

Fig.3. Temperature difference on cooling sleeve surface for various coolant flow rate at 12000rpm.

2) For Fig.2, all temperature test peaks appear at the 5th checkpoint with various coolant fluxes, and the similar conclusion, is also observed on the cooling sleeve surface. Evidently, the front half of spindle is not same to the rear half in heat dissipation, and the substructures outside the cooling unit may impact the heat transfer.

3) To compare 1st thermistor (close to the front-end of spindle) with 8th thermal resistance sensor (near the rear-end of spindle), there is only a slight difference in temperature, whose value is about $0.4^{\circ} \mathrm{C}$.

To analyze the heat sources and bearing arrangement of motorized spindle Setco231A240, the added findings are

1) In contrast with the heat generation of bearings, the motor armature generates more heat in operation. Consequently, there is still a higher temperature on the outer surface of spindle cooling sleeve than the front/rear end, though a lot of heat is taken away by the cooling passageway.

2) The bearings, as seen Fig.1, are arranged in Setco231A240 back to back, and therefore the axial load is distributed equally to each bearing set. As a result, the bearings have a same power loss 
and a little temperature difference.

The 1st, 5th and 8th checkpoints, based on the above experimental findings, were employed to further explore the effect of coolant temperature on spindle temperature field. The test results is also presented in Figs.4-5, where the coolant flow rate $(4.5 \mathrm{~L} / \mathrm{min})$ is fixed, the coolant temperature is regulated between $18^{\circ} \mathrm{C}$ and $22^{\circ} \mathrm{C}$ by setting oil cooler and the other test conditions are as above.

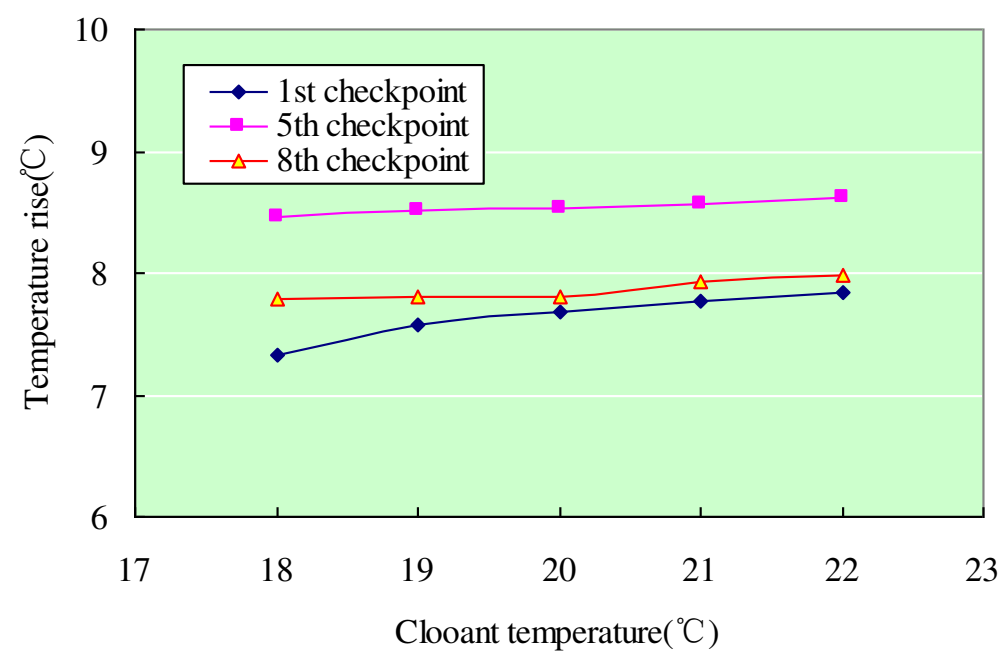

Fig.4. Temperature difference on cooling sleeve surface with oil cooler working temperature at $8000 \mathrm{rpm}$.

It is noteworthy that we also adjusted the setting of air conditioning synchronously so that the ambient temperature was always $2^{\circ} \mathrm{C}$ higher than coolant temperature.

1) The curves shown in both Figs.4 5 underline that the temperature of cooling sleeve rises with increasing the coolant temperature gradually. Clearly, higher operating temperature of cooling unit retards the convection heat transfer with spindle.

2) The temperature rise on cooling sleeve surface is nearly linear to the cooling oil temperature change. This clearly indicates that the cooling system has an indispensable role in reducing the spindle temperature.

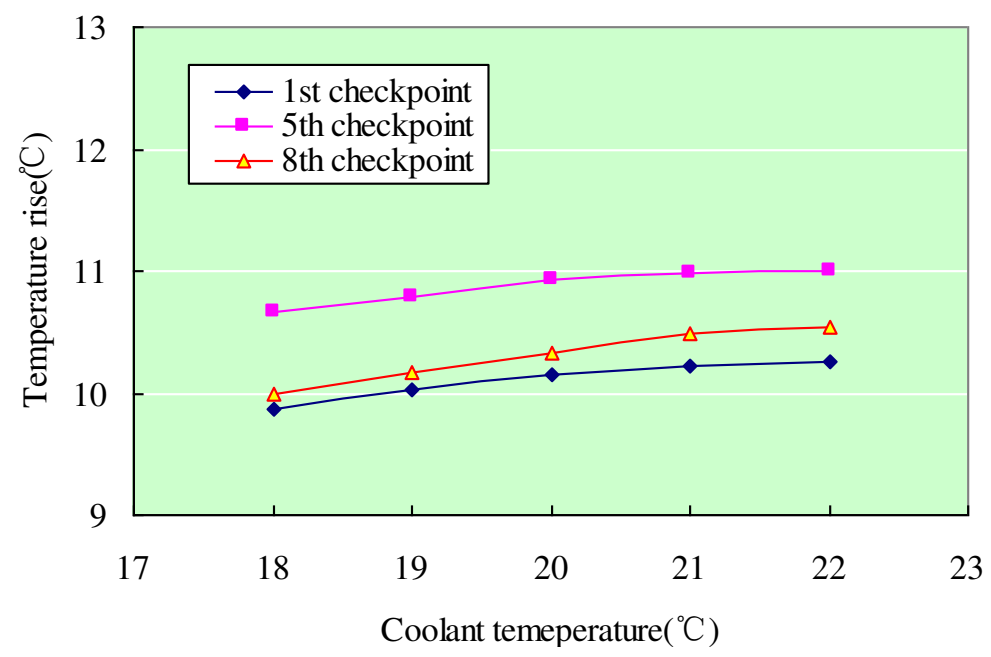

Fig.5. Temperature difference on cooling sleeve surface with oil cooler working temperature at 12000rpm.

The thermal energy taken away by coolant is another cogent report to assess the impact of a cooling unit on spindle temperature. Hence, we also gauged the temperature of discharged cooling oil, and the corresponding changes are described in Fig.6. 
1) The temperature rise of coolant emissions decreases little by little as we raise the oil cooler working temperature from $18^{\circ} \mathrm{C}$ to $22^{\circ} \mathrm{C}$. It is noticeable that the heat absorbed by cooling oil is reduced with higher coolant temperature.

2) The discharged cooling oil temperature change is very small, see Fig.6, the decrease are less than $0.4^{\circ} \mathrm{C}$ at $8000 \mathrm{rpm}$. The variation, by contrast, is more $\operatorname{slight}\left(0.3^{\circ} \mathrm{C}\right)$ when the spindles operate at higher speed $(12000 \mathrm{rpm})$.

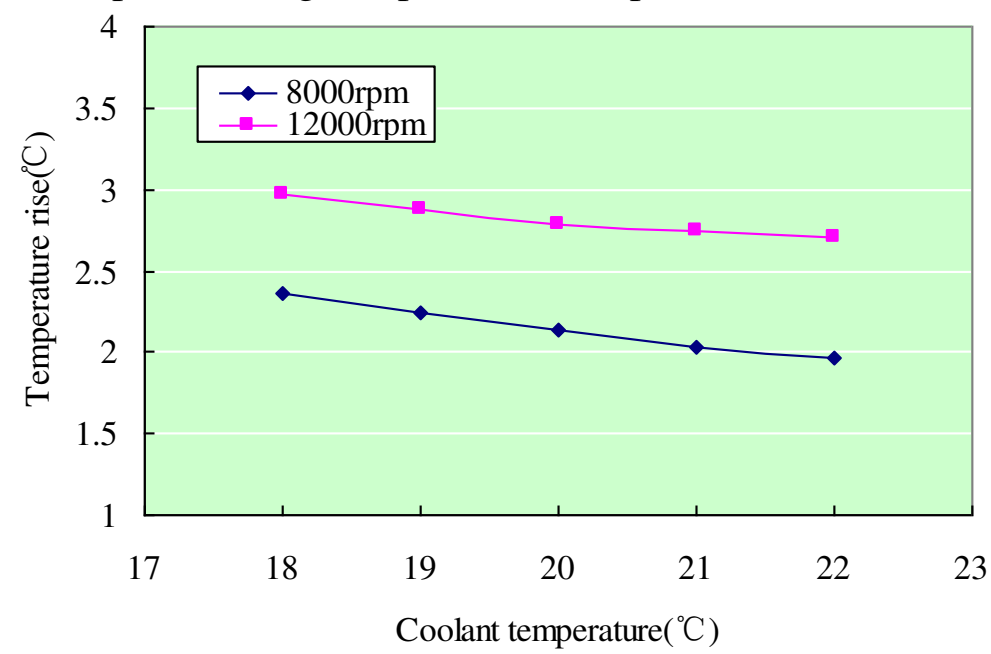

Fig.6. Temperature variation of discharged cooling oil under different oil cooler working temperature.

\subsection{Regressive analysis}

To closely examine the data shown in Figs.2 3, one further finding is that the data on both sides of the $5^{\text {th }}$ checkpoint are almost linear. Figs.7 8 presents the corresponding results of linearization after regressive analysis. It's obvious the structural constraints outside a coolant passage significantly impact the heat dissipation of spindle.

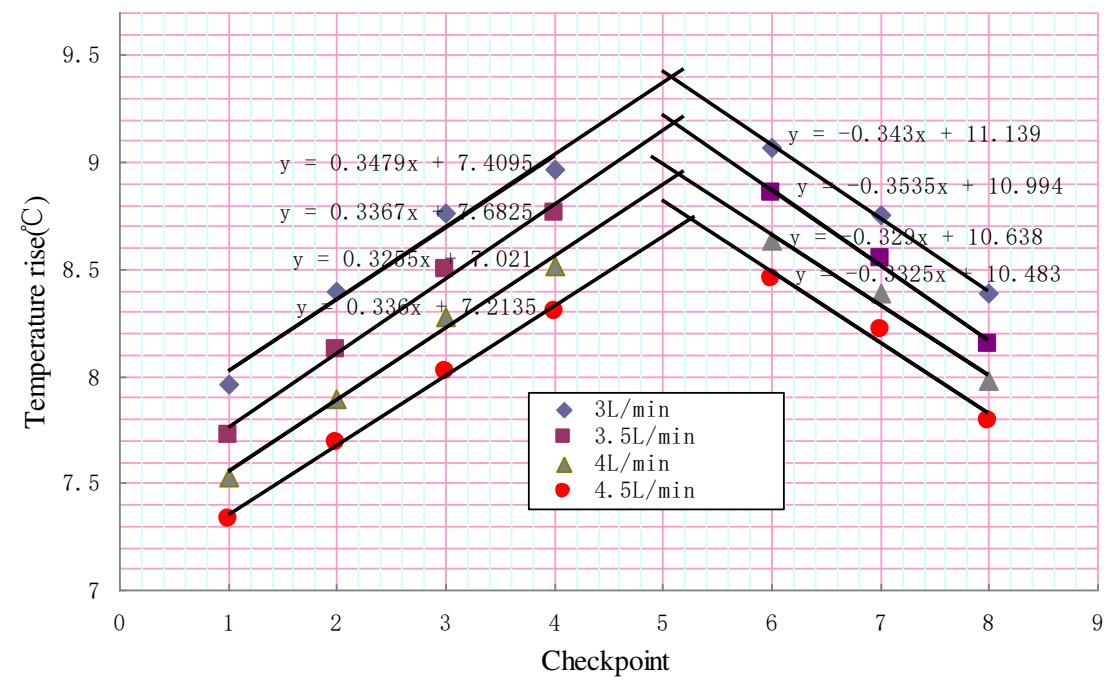

Fig.7. Regressive analysis for $8000 \mathrm{rpm}$. 


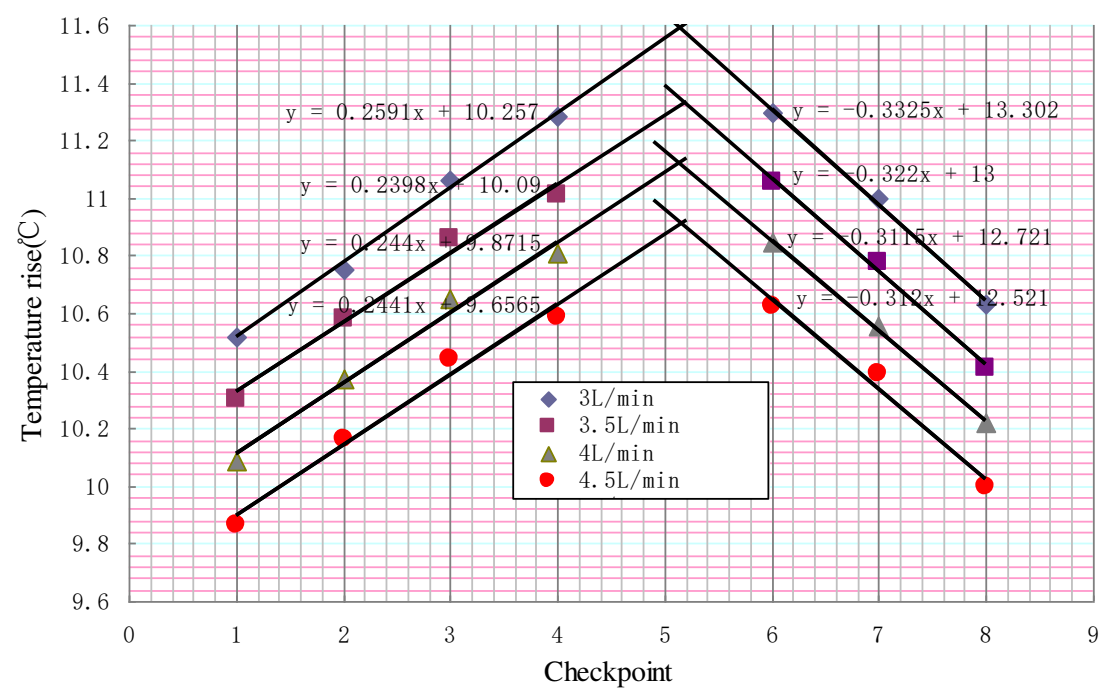

Fig.8. Regressive analysis for $12000 \mathrm{rpm}$.

1) In the front half of the spindle (from the 1st checkpoint to 4th checkpoint), the slope change of regression lines is very little under different coolant flow rate $(0.024$ for $8000 \mathrm{rpm}$, and 0.021 for 12000rpm). As such, the corresponding regression lines are almost parallel in the rear half of spindle, the variations of whose slopes are 0.022 for $8000 \mathrm{rpm}$ and 0.02 for 12000rpm separately. This indicates that the heat transfer capacity between the spindle parts is almost not affected by the flow rate of a coolant.

2) There is a clear difference in the slopes of regression lines for the front and rear half of spindle, whose mean values are 0.339 and 0.336 for $8000 \mathrm{rpm}$ and 0.32 and 0.247 for 12000rpm respectively. As a result, the intersections between regression lines, namely, the temperature peaks, appear at different positions when changing the operation conditions, see Figs.7 8, but these positions are still very close to the $5^{\text {th }}$ checkpoint. Evidently, the location of the spindle temperature peak depends on the structural constraints outside the cooling unit than the change of working conditions.

3) From Figs.7 8, a further finding is that the slopes of regression lines for the front half of spindle are closer than the rear half of spindle. Clearly, the structural constraints outside the front end of the spindle show more stable in the spindle temperature field. And this also provides a theoretical basis for researchers to choose the first half of a spindle as the thermal analysis object.

\section{A factor to assess the coolant unit effect on temperature}

Based on the above regression analysis, one obvious conclusion is that the structural constraints outside a coolant passage significantly impact the heat dissipation of a spindle. It is absolutely essential to create a detailed model for the whole spindle for discussing the heat transfer in depth. Considering the complexity of spindle structure, however, this will result in a complex model and then the data overhead increases greatly. To present a simple and practical model, many papers aim at one end of the spindle; nevertheless, they ignore the substructures between the front and rear end of a spindle, which significantly impact the accuracy of thermal estimation. So, the "peak temperature surface" is proposed and the structural factors are constructed to describe the effect of the structural constraints on the temperature peak of spindle. And this benefits the simplification thermal estimation models.

\subsection{Peak temperature surface}

According to the above regression analysis, the temperature peaks on the outer surface of the 
spindle will appear at a specific area under various operation conditions. From Figs.7 8, this area is very narrow, approximately a plane. Therefore, we may use the plane $x=L_{P}$ to represent the peak region, as seen in Fig.9. According to the regression analysis $x=L_{P}$ can be determined by

$$
\left\{\begin{array}{l}
y=\bar{m}_{R} x+\bar{b}_{R} \\
y=\bar{m}_{F} x+\bar{b}_{F}
\end{array}\right.
$$

where $\bar{m}_{F}$ and $\bar{m}_{R}$ are the mean values of first order terms for the front and rear halves of spindle, and $\bar{b}_{F}$ and $\bar{b}_{R}$ represent the corresponding mean values of constant terms, respectively.

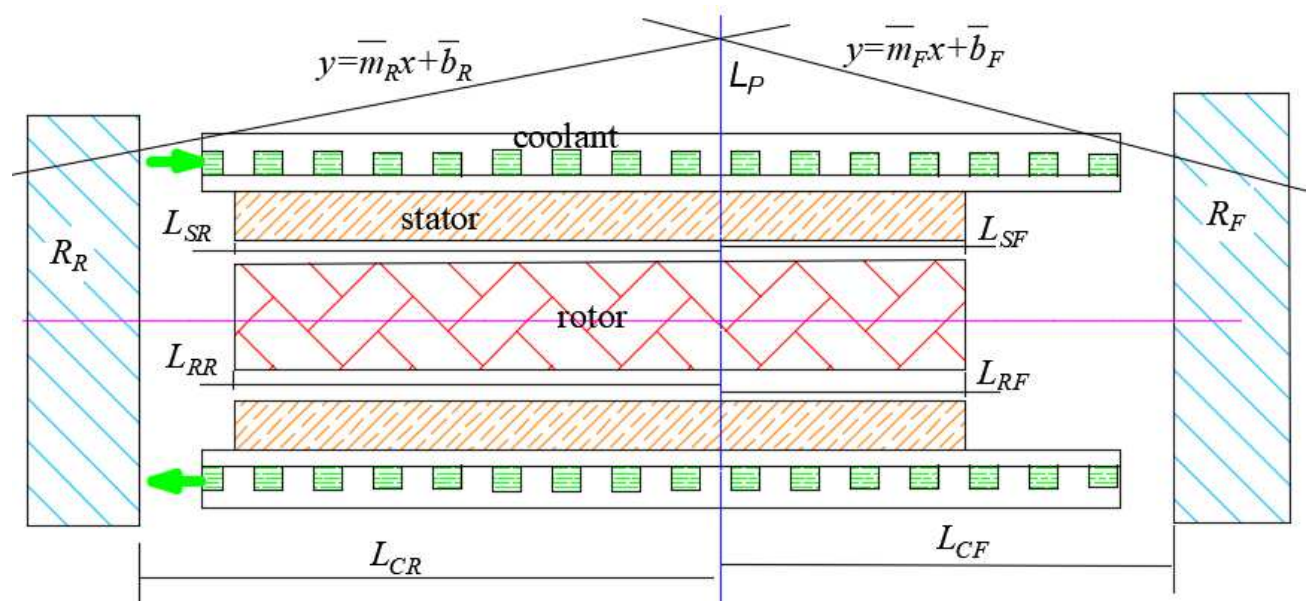

Fig.9. Structure sketch of the motorized spindle

Obviously, an indisputable fact is that the temperature is the highest at $x=L_{P}$, and so we may assume that heat can only be transferred from this plane to the front and rear ends of spindle, namely the heat exchange is carried out independently on both sides of the plane $x=L_{P}$. As a result, the spindle can be divided into two parts so as to simplify the thermal model and control of the spindle.

\subsection{A scaling factor}

Fig.9 shows a structure sketch of the motorized spindle, in which $R_{F}$ and $R_{R}$ are the structural constraints of front and rear spindle ends, and $L_{F}$ and $L_{R}$ denote the distances between the temperature peak plane $x=L_{P}$ and the spindle ends separately. Based on $x=L_{P}$, the cooling passageway is divided into two parts: $L_{C F}$ and $L_{C R}$. The stator and rotor of spindle motor, too, are divided into two parts.

To further describe the effect of coolant unit, stator and rotor on the temperature field of spindle, Let's set the corresponding factors as follows 


$$
\left\{\begin{array}{l}
K_{C}=L_{C F} /\left(L_{C F}+L_{C R}\right) \\
K_{S}=L_{S F} /\left(L_{S F}+L_{S R}\right)
\end{array}\right.
$$

Considering the consistency in length, the stator and rotor have the same scaling factor.

$$
K_{R}=K_{S}
$$

Clearly these structural coefficients benefit the thermal model development and determination of spindles.

\section{Application in thermal estimation of spindles}

To apply the proposed structure scaling factor to create a more simple and efficient thermal estimation model is the end of this study. The validity of the coefficient, of course, also needs to be proved. For this reason, we need select a research object to build the corresponding thermal networks and subsequently determine it for contrast.

\subsection{Thermal networks model with a cooling system}

Based on the experimental findings in section 2, the heat transfer model for the front half of motorized spindle was develop with the help of constructed scaling factors, as shown in Fig.10, where the bearings' substructures, contact between parts, spindle motor heating, coolant and lubricant system are all taken into account. Some idealizations were also done to facilitate modeling.

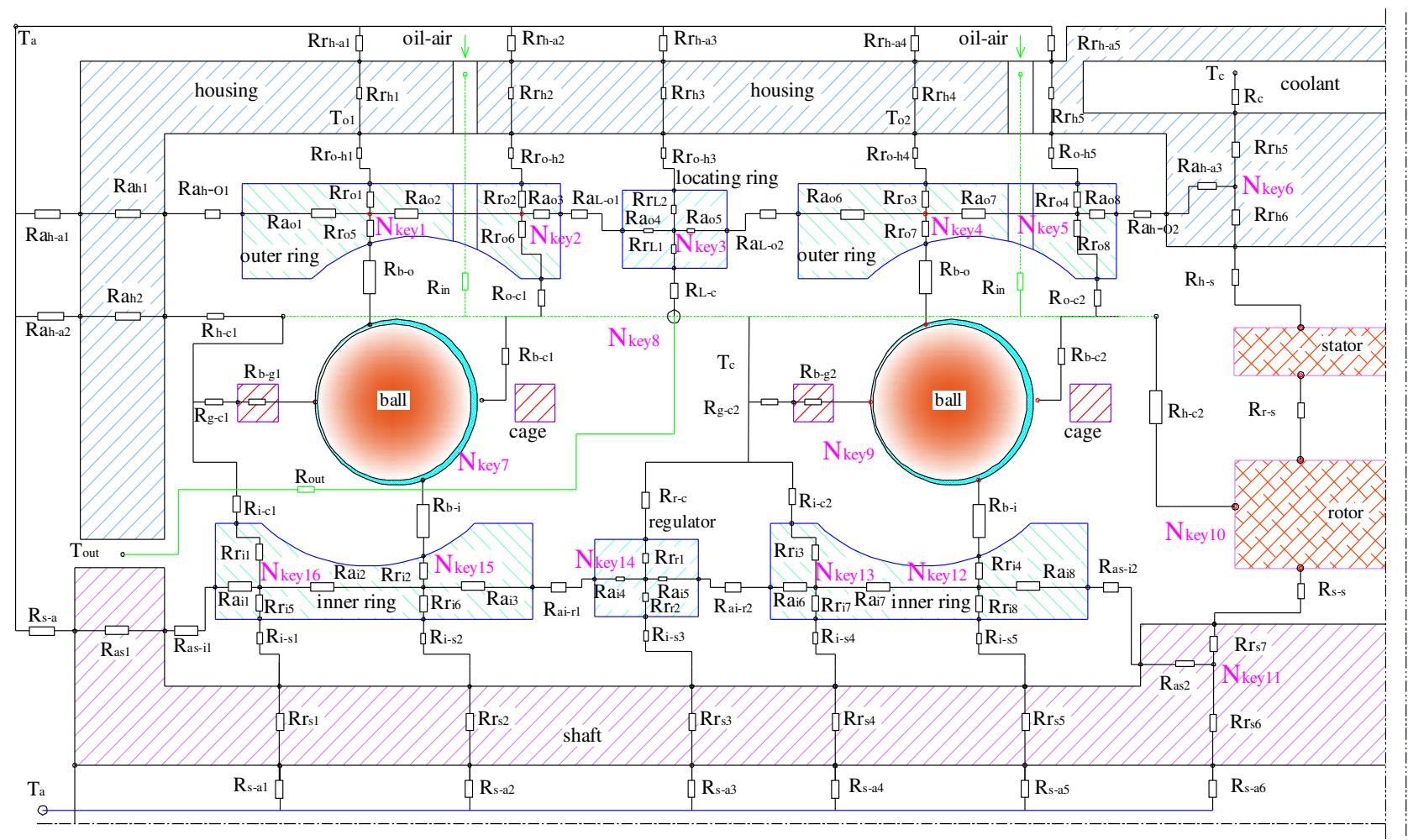

Fig.10. Thermal model for the motorized spindle with a cooling unit.

1) The rotor and stator were both seen as cylinders, the structure after simplifying is as presented in Fig.10.

2) For the surroundings outside a pair of front bearings, we referred to our previous work [26] and accordingly reduced them. 
3) In view of the above-mentioned facts in section 2, the coolant system is divided into two parts, namely only the front half of the rotor, stator and cooling passageway is integrated into the proposed thermal grid model with the help of the scaling factors when we predict the front-end temperature of the spindle.

4) The rotor heating is assumed to be a separate point thermal source, so is the power loss of bearing and stator. They are arranged separately.

In Fig.10, the improved node planning for ball bearings in Ref. [26] is employed. More corresponding descriptions on the resistance determination are also classified and further summarized as the tables 1 2 below, where the thermal contact transfer between parts, the heat exchange between various spindle parts and fluid media, etc. can be evaluated by the models given.

Table 1. Resistances on thermal conduction

\begin{tabular}{|c|c|c|c|c|c|}
\hline \multirow{2}{*}{\multicolumn{3}{|c|}{$\frac{\text { description }}{\text { ball-raceway }}$}} & employed model & \multirow{2}{*}{$\frac{\text { applicable object }}{R_{b-i}, R_{b-o}}$} & \multirow{2}{*}{$\frac{\text { reference }}{\text { Ref. [27] }}$} \\
\hline & & & $R=\frac{1}{\pi}\left(\frac{a}{b}\right)\left(k_{D} a \sqrt{\frac{\eta_{e f f}}{\alpha_{\Delta} \cdot \rho_{\text {eff }}}}\right)^{-1}$ & & \\
\hline \multirow{3}{*}{ 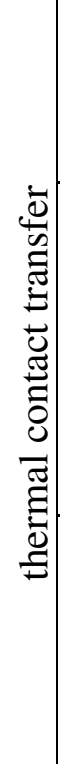 } & 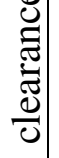 & $\begin{array}{l}\text { housing-regulator, } \\
\text { housing-locating ring }\end{array}$ & $R=\frac{1}{A h_{\text {cont }}}=\frac{L_{g}}{A \cdot k_{D f}}$ & $\begin{array}{l}R_{r o-h 3} \\
R_{i-s 3}\end{array}$ & Ref. [28] \\
\hline & 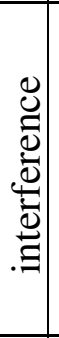 & $\begin{array}{l}\text { shaft-bearing inner bore, } \\
\text { rotor-shaft, } \\
\text { housing-outer ring, } \\
\text { shaft-inner ring, } \\
\text { bearing-retainer, } \\
\text { bearing-regulator }\end{array}$ & $R=\frac{1}{A h_{\text {cont }}}=\frac{L_{g}\left(k_{D_{1}}+k_{D_{2}}\right)}{2 A \cdot A_{r}^{*} \cdot k_{D_{1}} \cdot k_{D_{2}}}$ & $\begin{array}{l}R_{i-s 1} \sim R_{i-s 2}, R_{i-s 4} \sim R_{i-s 5}, \\
R_{s-s}, \\
R_{a h-o 1}, \\
R_{a s-i 1}, R_{a s-i 2}, \\
R_{a L-o 1} \sim R_{a L-o 2}, \\
R_{a i-r 1} \sim R_{a i-r 2} \\
\end{array}$ & Ref. [28] \\
\hline & 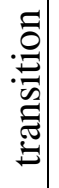 & $\begin{array}{l}\text { housing-outer ring, } \\
\text { rotor-housing }\end{array}$ & $\left\{\begin{array}{c}R=L_{g}\left(A\left[A_{r}^{*} k_{D}^{*}+\left(1-A_{r}^{*}\right) k_{D f}\right]\right)^{-1} \\
k_{D}^{*}=2 k_{D_{1}} k_{D_{2}}\left(k_{D_{1}}+k_{D_{2}}\right)^{-1}\end{array}\right.$ & $\begin{array}{l}R_{r o-h 1} \sim R_{r o-h 2}, R_{r o-h 4} \sim R_{r o-h 5}, \\
R_{h-s}\end{array}$ & Ref. [28] \\
\hline \multicolumn{3}{|c|}{$\begin{array}{l}\text { one-dimensional transfer within } \\
\text { the parts themselves }\end{array}$} & $R=\ln \left(d_{e x t} / d_{\text {int }}\right)\left(2 \pi k_{D} L\right)^{-1}$ & $\begin{array}{l}R_{r h 1 \sim 6}, R_{r s 1 \sim 7}, R_{r o 1 \sim 8}, R_{a o 1 \sim 8}, \\
R_{r i 1 \sim 8}, R_{a i 1 \sim 8}, R_{a h 1 \sim 2}, R_{a s 1}\end{array}$ & Ref. [29] \\
\hline
\end{tabular}

Besides, we also arrange $R_{g-c 1}$ and $R_{g-c 2}$ to assess the heat exchange between fluid media and cages, whose determination was presented in paper [26].

Table 2. Nu for the heat convection resistances.

\begin{tabular}{|c|c|c|c|c|}
\hline \multicolumn{2}{|c|}{ description } & employed model & $\begin{array}{l}\text { applicable } \\
\text { object }\end{array}$ & reference \\
\hline \multirow{4}{*}{ 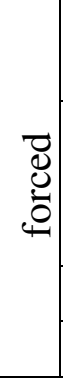 } & balls- oil air mixture & $N u=\left(1.2+0.53\left(\frac{\rho_{e f f} D_{b}}{\eta_{e f f}} \cdot \frac{\omega_{c} d_{m}}{2}\right)^{0.64}\right) \cdot\left(\frac{\eta_{e f f}}{\alpha_{d} \cdot \rho_{e f f}}\right)^{0.3}\left(\frac{\left.\eta\right|_{T_{\text {wath }}}}{\left.\eta\right|_{T_{\text {wan }}}}\right)$ & $R_{b-c 1}, R_{b-c 2}$ & Ref. [29] \\
\hline & inner ring-oil air mixture & $\left\{\begin{array}{lr}N u=2 & T a<41 \\
N u=0.167\left(\rho g_{r}\left(r_{i n} \omega\right) \mu^{-1} \sqrt{g_{r} / r_{i n}}\right)^{0.69} P_{r}^{0.4} & 41<T a<100 \\
N u=0.401\left(\rho g_{r}\left(r_{i n} \omega\right) \mu^{-1} \sqrt{g_{r} / r_{i n}}\right)^{0.5} P_{r}^{0.4} & 100<T a\end{array}\right.$ & $R_{i-c 1}, R_{i-c 2}$ & Ref. [30] \\
\hline & air-shaft end & \multirow{2}{*}{$\begin{array}{cl}N u=0.4 \sqrt{R_{e}} P_{r}^{\frac{1}{3}} & R_{e}<2.5 * 10^{5} \\
N u=0.238 R_{e}^{0.8} P_{r}^{0.6} & R_{e}>3.2 * 10^{5}\end{array}$} & $R_{s-a}$ & \multirow{2}{*}{ Ref. [31] } \\
\hline & rotor-oil air mixture & & $R_{h-c 2}$ & \\
\hline
\end{tabular}




\begin{tabular}{|c|c|c|c|c|}
\hline & air-inner surface of shaft & $\left\{\begin{array}{ccc}N u & =30.5\left(V_{s} D_{s} / v_{a}\right)^{-0.0042} & R_{e} \geq 9600 \\
N u & =\left(V_{s} D_{s} / v_{a}\right)^{0.37} & 7300 \leq R_{e}<9600 \\
N u=0.00308\left(V_{s} D_{s} / v_{a}\right)+4.432 & & 7300<R_{e}\end{array}\right.$ & $R_{s-a 1} \sim R_{s-a 6}$ & Ref. [32] \\
\hline \multirow{5}{*}{$\stackrel{\Xi}{\Xi}$} & $\begin{array}{l}\text { air-housing in axial } \\
\text { direction }\end{array}$ & $N u=\left\{0.825+\frac{0.387\left(R_{e}\right)^{1 / 6}}{\left[1+\left(0.492 / P_{r}\right)^{9 / 16}\right]^{8 / 27}}\right\}$ & $\begin{array}{l}R_{a h-a 1} \sim \\
R_{a h-a 2} \\
\end{array}$ & Ref. [33] \\
\hline & $\begin{array}{l}\text { air-housing in radial } \\
\text { direction }\end{array}$ & \multirow{4}{*}{$N u=\left\{0.6+\frac{0.387\left(R_{e}\right)^{1 / 6}}{\left[1+\left(0.559 / P_{r}\right)^{9 / 16}\right]^{7 / 27}}\right\}$} & $\begin{array}{l}R_{r h-a 1} \sim \\
R_{r h-a 5} \\
\end{array}$ & \multirow{4}{*}{ Ref. [34] } \\
\hline & regulator-oil air mixture & & $R_{r-c}$ & \\
\hline & locating ring-oil air & & $R_{L-c}$ & \\
\hline & outer rings-oil air & & $R_{o-c 1}, R_{o-c 2}$ & \\
\hline
\end{tabular}

Furthermore, $R_{c}$ is planned to represent the convective resistance of cooling system, and $R_{r-s}$ characterizes the heat transfer capacity between rotor and stator. And the detailed description of these two thermal resistances is arranged in section 4.2.2 and section 4.2.3 separately.

\subsection{Models for thermal discussion}

\subsubsection{Heat sources}

The heat of motorized spindle is composed of the bearings' energy consumption and the armature energy loss.

\section{1) Motor}

The energy expenditure caused by spindle motor heating is mainly composed of copper loss, core loss and mechanical loss, which can be expressed as

$$
P_{M}=P_{f}+P_{h}+P_{c}+P_{c u}
$$

If only the front half of spindle is analyzed, the heat generation of spindle motor is calculated by

$$
P_{M S}=K_{S}\left(P_{f}+P_{h}+P_{c}+P_{c u}\right)=K_{S} P_{f}+K_{S} P_{h}+K_{S} P_{c}+K_{S} P_{c u}
$$

Here, $P_{f}, P_{h}, P_{c}, P_{c u}$ denote the mechanical loss, hysteresis loss, eddy current loss and copper loss, separately. They are estimated by [35]

$$
\left\{\begin{array}{c}
P_{f}=\left(\frac{h}{\delta_{\text {air }}}+\left(\frac{100}{R_{e}}\right)\right) \pi \rho_{\text {air }} \omega_{m}{ }^{3} R^{4} L \\
P_{h}=b B_{\max }^{2} f \\
P_{c}=\frac{\pi^{2}}{6 \rho_{R}}\left(f B_{\max }\right)^{2} \delta_{s}^{2} v_{s} \\
P_{c u}=I_{L}{ }^{2} R_{L}
\end{array}\right.
$$

where $\rho_{\text {air }}$ is the air density, $\omega_{m}$ is the spindle speed, $L$ and $R$ are the rotor length and diameter, $h$ is the protrusion of rotor end, $\delta_{\text {air }}$ is the air gap between rotor and stator, $R_{e}$ is the reynolds number, $C_{b}$ is the constant relying on material properties, $B_{\max }$ is the maximum of magnetic induction, $f$ is the magnetic field frequency, $v_{s}$ and $\delta_{s}$ are the volume and thickness of silicon steel, $\rho_{R}$ is the 
resistivity, $I_{L}$ and $R_{L}$ represent the current and resistance of stator/rotor winding, separately.

\section{2) Bearing}

To assess the energy loss of rolling bearing by the experimental models is first employed, for example the best-known Palmgren's formulas[36]. On this basis, many improved forecasting was proposed successively[5,24]. Despite some enhancement of the forecast accuracy, more parameters are integrated, which makes the evaluation of heat generation more difficult. In this discussion, we still referred to Palmgren's fingdings to calculate the power loss of bearings.

$$
W_{T}=W_{v}+W_{F}+W_{s}
$$

Here, $W_{T}$ is the total friction heat, and how to determine the sub sources $W_{v}, W_{F}$ and $W_{s}$ is detailed as Table 3 below.

Table 3. Sub sources of bearing heating

\begin{tabular}{l|l|l|l}
\hline sub source & employed model & applicable object & reference \\
\hline$W_{F}$ & $\int_{0}^{\frac{2 \pi}{\omega_{r}}} f_{1} P_{1} d_{m} \cdot \omega_{r} d(t)$ & $\begin{array}{l}\text { the friction heat induced by the } \\
\text { radial and axial loads }\end{array}$ & \\
\hline$W_{v}$ & $\left\{\begin{array}{c}W_{v}=\int_{0}^{\frac{2 \pi}{\omega_{r}}} M_{v} \cdot \omega_{r} d(t) \\
M_{v}=f_{0}(v \cdot n)^{2 / 3} d_{m}^{3} / 1000 \quad v \cdot n \geq 2000 \\
M_{v}=160 f_{0} d_{m}^{3} / 1000 \quad v \cdot n<2000\end{array}\right.$ & $\begin{array}{l}\text { the power loss relating to the } \\
\text { lubricant viscosity }\end{array}$ & Ref. [36] \\
\cline { 1 - 2 } & $Z_{b} \cdot\left(\frac{6 \pi Q_{i j A} \mu_{s i} a_{i} \sum_{i}}{8}+\frac{6 \pi Q_{o j A} \mu_{s o} a_{o} \sum_{o}}{8}\right)$ & $\begin{array}{l}\text { the energy loss caused by the spin } \\
\text { motion of bearing balls }\end{array}$ & \\
\hline
\end{tabular}

\subsubsection{Heat exchange capacity about the cooling channel of a spindle}

The forced convection through cooling channel is an efficient way to dissipate heat. According to our latest work [25], the coolant passage can be regarded as a tube with the inner diameter $d_{t}$. Referring to the relevant finding summarized in the book [37], the corresponding thermal resistance to describe the heat exchange capacity of cooling passageway is formulated as below.

$$
R_{t h}=\frac{1}{A h_{v}}=\frac{1}{A}\left(\frac{d_{t}}{k_{D} N u}\right)
$$

where $h_{v}$ is the convection heat transfer coefficient, $k_{D}$ is the thermal conductivity of coolant, and $A$ represents the inner area of passage.

$$
A=\pi^{2} d_{t} D_{t} n_{l}
$$

Here, $D_{t}$ is the helix diameter of spiral cooling channel, and $n_{l}$ denotes the number of helix turn.

In addition, $N u$ in Eq.(8) is the Nusselt number to describe the heat transfer capacity between coolant and passageway, which can be determined through introducing the Reynolds number $R_{e}$ and 
the Prandtl number $P_{r}$ [38].

$$
N_{u}=0.023 R_{e}^{0.8} P_{r}^{0.4}=0.023\left(\rho_{l} V_{l} d_{t} / \eta_{l}\right)^{0.8}\left(\eta_{l} /\left(\rho_{l} \alpha_{d l}\right)\right)^{0.4}
$$

where $\eta_{l}, \alpha_{d l}, V_{l}$ are the viscosity, diffusion coefficient and circuit flow rate of coolant separately.

So,

$R_{t h}=\frac{1}{A}\left(\frac{d_{t}}{k_{D} 0.023\left(\rho_{l} V_{l} d_{t} / \eta_{l}\right)^{0.8}\left(\eta_{l} /\left(\rho_{l} \alpha_{d l}\right)\right)^{0.4}}\right)=43.478 \times \frac{d_{t}^{0.2}}{A} \times \frac{1}{k_{D}\left(\rho_{l} /\left(\eta_{l} \alpha_{d l}\right)\right)^{0.4} V_{l}^{0.8}}=\frac{43.478 \xi}{\pi^{2} \varsigma}$

Here,

$$
\left\{\begin{array}{c}
\xi=\frac{1}{k_{D}\left(\rho_{l} /\left(\eta_{l} \alpha_{d l}\right)\right)^{0.4} V_{l}^{0.8}} \\
\zeta=d_{t}^{0.8} D_{t} n_{l}
\end{array}\right.
$$

Obviously, $\xi$ relies on the operation conditions than the structure parameters of a cooling unit. $\zeta$, by contrast, is closely related to the structural parameters of coolant passage.

Only the front end of a spindle, for the purpose of a simpler thermal assessment, was usually modeled. But the existing papers can't show a scaling factor to describe what extent the cooling system impacts the heat dissipation of front/rear spindle end exactly. Based on Section 3, a structural scaling factor $K_{C}$ is employed to estimate the corresponding influence of coolant passageway on the heat exchange of front spindle end.

$$
R_{c}=K_{C} \cdot R_{t h}=\frac{43.478 K_{C} U}{\pi^{2} d_{t}^{0.8} D_{t} n_{l}}
$$

\subsubsection{Heat exchange between rotor and stator}

Rotor heating accounting for about $1 / 3$ of total energy loss of a spindle motor is transferred through the air. This heat exchange can be regarded as a free convection in the confined space. Paper [35] presents a simplified model to calculate the heat transfer capacity.

$$
R_{M r-s}=\frac{1}{28 A\left(1+\sqrt{0.5 v_{c}}\right)}
$$

where $R_{M r-s}$ is the heat transfer resistance between rotor and stator of motor, $A$ is the heat convection area between rotor and stator and $v_{c}$ is the linear velocity of rotor.

Certainly, $R_{M r-s}$ is also separated into two parts by the temperature peak plane. For the front half of spindle, the scaling factor $K_{S}$ can be used to determine the corresponding thermal resistance.

$$
R_{F M r-s}=\frac{K_{S}}{28 A\left(1+\sqrt{0.5 v_{c}}\right)}
$$




\subsection{Simplification and solution}

As mentioned, the developed thermal grid seems to be a more complex model because the cooling and lubricant units are considered and the substructures and fit between parts as well. Yet, the complexity of a network depends more on the node number, especially the nodes with more than two inputs. Further analysis shows that there are only 16 such key nodes, as you can see the marked $N_{\text {key1 }} \sim N_{\text {key16 }}$ in Fig.10. Based on the series and parallel theory of Ohm's law, the resistances between two key nodes, moreover, can be reduced as an equivalent thermal impedance. The simplified model, as shown in Fig.11, is not complicated.

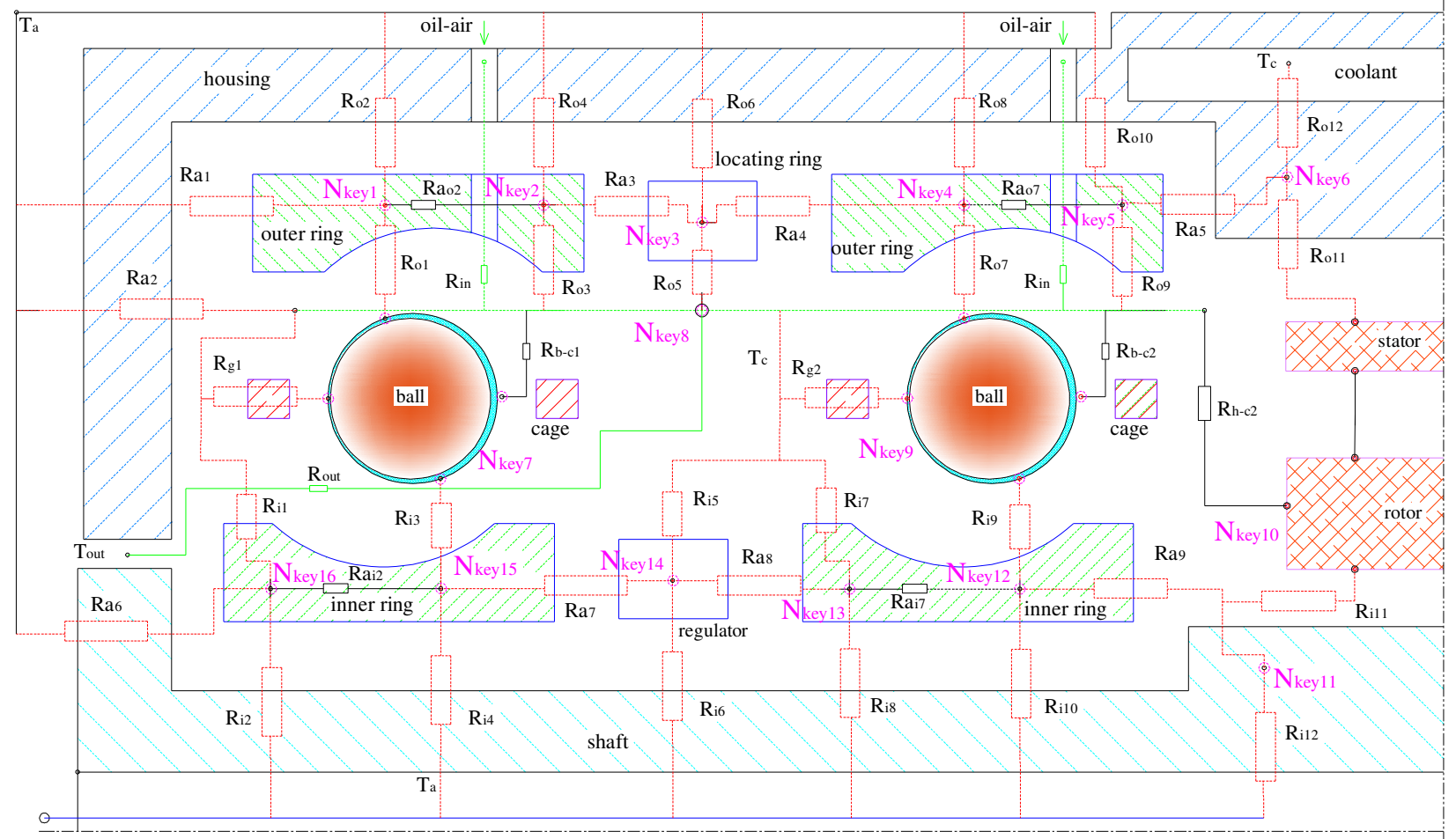

Fig.11. Simplified thermal grid by series and parallel theory.

In this discussion, the corresponding heat flux model of each key node in Fig.11 can be first built, and next we can establish a heat balance equation group for the whole thermal grid as below.

$$
\sum_{i=1}^{N} \sum_{j=1, j \neq i}^{N}\left(T_{i}-T_{j}\right) R_{i j}^{-1}+\sum \mathcal{Q}_{g}=0
$$

where $R_{i j}, \mathcal{Q}_{g}$ and $T_{i, j}$ denote the resistance, heat generation capacity and node temperature respectively.

Using the popular Newton Raphson method, the node temperature can be easy to obtain and then can assist us to verify the constructed model and structural scaling factors. Meanwhile, this also is of great benefit for further exploring the thermal exchange of spindle.

\section{Results and discussion}

To validate the planned thermal forecasting model for the motorized spindle and the proposed scaling factors to describe how the coolant unit influences the heat transfer of front/rear half spindle as well, a comparison with simulation results is need. In contrast to the surface temperature of spindle housing, the heating of spindle bearings can better report the temperature variation and even the thermal error of spindles, so the outer ring temperature of front bearing 7009AC is selected as a 
reference for the sake of better validation. The testing scheme is the same as illustrated in Fig.1, and the experimental conditions under various operation settings of oil cooler are as mentioned in section2.2. The corresponding measurements are separately presented in Fig.12 and Fig.13.

The thermal network model, equation group and iterative algorithm described in section 4, meanwhile, are employed to obtain the numerical solution of outer ring temperature when the coolant temperature are changed. The contrast with the experimental results is described in Fig.13. The similar experimental study for coolant flow flux is also carried out, and the corresponding test values are illustrated in Fig.12.

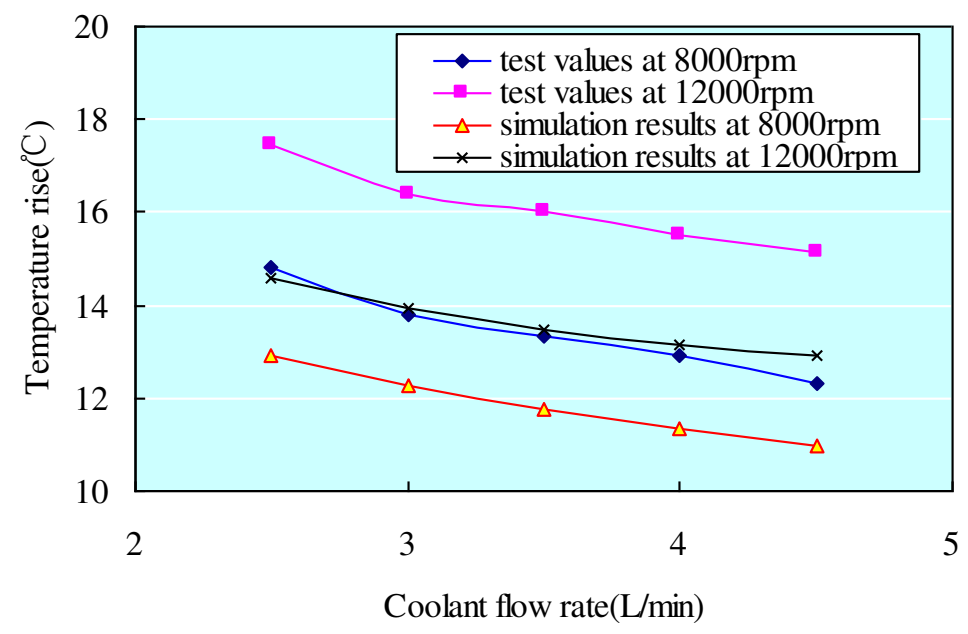

Fig.12. Contrast on bearing heating under different coolant flow rate.

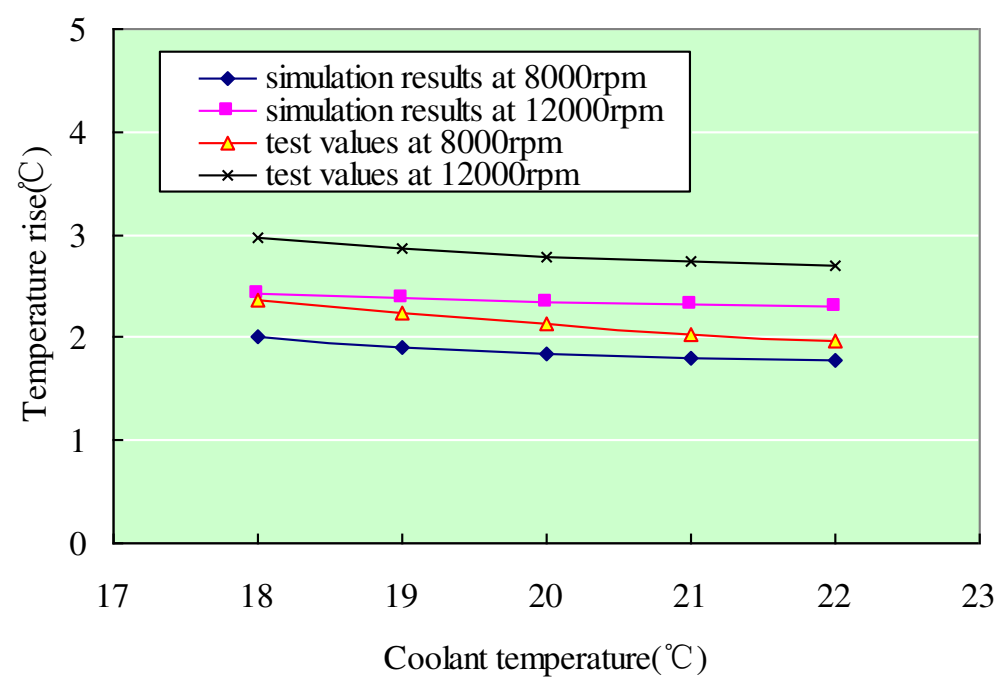

Fig.13. Contrast on discharged coolant temperature under different oil cooler working temperature.

It has been demonstrated by a number of studies that the rotation rate has a more visible effect on bearing heating than lubricant and air flow as well. Therefore, we measured the thermal growth with the increased speed to further validate the proposed model, too. The contrast with simulation based on Matlab is shown in Fig.14.

Note that the assumptions for numerical results are

1) The temperature variation is linear from the inlet to the outlet of coolant passage.

2) Given the spindle bearing arrangement, we believe both the applied axial load and the thermal expansion-induced preload in operation have an equal distribution in bearings

3) The temperature of discharged oil-air is used to represent the atmosphere in spindle cavity. 


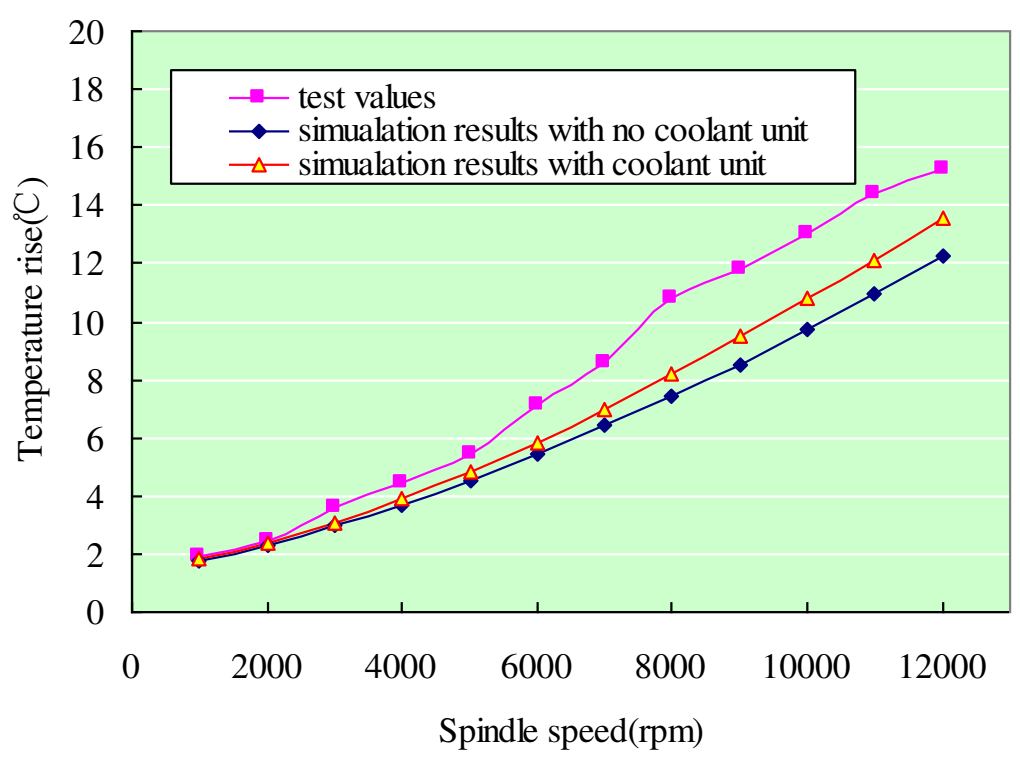

Fig.14. Contrast on bearing temperature with changing spindle speed.

From Figs.12 14, there is an obvious good agreement between test values and forecasting results. And this validates the simplified thermal network by the structural scaling factors for cooling system and motor armature. Compared with current works, a more accurate estimation of real spindle temperature can be carried out by the developed model for motored spindles.

1) Just like the numerical results in bearing temperature, the test results (see Fig.12) also decrease when raising the cooling oil flow rate. Obviously, more heat can be taken away with more coolant supply. But both experimental and numerical curves indicate that there is no same level in temperature reduction (no more than $2.5^{\circ} \mathrm{C}$ at $8000 \mathrm{rpm}$ and $2.3^{\circ} \mathrm{C}$ at $12000 \mathrm{rpm}$ ) when the coolant flow rate is raised from $2.5 \mathrm{~L} / \mathrm{min}$ to $4.5 \mathrm{~L} / \mathrm{min}$. It is obvious that a reasonable coolant flux is needed when the energy efficiency of oil cooler is factored.

2) From Fig.13, the temperature of discharged cooling oil has a very small rise with the decrease of oil cooler operating temperature. The variation, just liking the depictions of Figs.4 5, is almost linear. Clearly, the operating temperature of oil cooler, only has a little effect in cooling spindle. As a result, to set the oil cooler operating at $2{ }^{\circ} \mathrm{C}$ lower than room temperature may be a more cost-effective way.

3) Through solving the developed thermal grid of front half spindle with a coolant system considered, the forecast temperature of bearing outer ring is obtained and described in Fig.14. The similar work for the spindle with no cooling unit is also done for further validation, and the corresponding tolerances compared with measurements are about $10 \%$. The difference is less than $8 \%$, in comparison with a coolant system. Evidently, the simulation findings with a coolant unit are closer to the test conclusions than no cooling unit. So, we can more accurately predict the spindle temperature when the coolant system effect is considered by introducing the structural scaling factors.

To a certain extent, the temperature forecasting values based on simulation still deviate from the test results, however. Besides the prediction error mentioned above under different spindle speeds, the deviation, for varied coolant flux, is near to $1.8^{\circ} \mathrm{C}$ when the spindle operates at $8000 \mathrm{rpm}$, and this maximum is $2.5^{\circ} \mathrm{C}$ at $12000 \mathrm{rpm}$. Similarly, the error approaches $0.3^{\circ} \mathrm{C}$ for $8000 \mathrm{rpm}$ and $0.5^{\circ} \mathrm{C}$ for $12000 \mathrm{rpm}$ with coolant temperature though the values are not large.

1) The various sub heat sources of bearings, as we all know, are induced by different mechanism, meanwhile, they are also scattered at different location of bearings. Yet, in this paper, the 
bearing heat was determined by the global model and then was assumed to be a point placed in ball center. Additionally, the scaling factors were constructed to consider the effect of structural constraints on heat transfer, but both stator and rotor were still reduced to point heat sources. Compared with the real heat generation of motorized spindles, there is a certain gap.

2) To create an efficient engineering model, some idealizations for spindle substructures were done. Yet, the corresponding heat transfer is also ignored in these simplifications. And this is another contribution to forecasting error.

3 ) As is known to all, the heat convection between spindle and air/liquid under vibration will be different from the corresponding heat exchange under no vibration and the contact state between parts as well. These changes can affect the thermal contact and convection resistances. Obviously, neglect of the heat transfer change under vibration in our temperature assessment cannot match facts.

4) The coolant can absorb and then take away a great quantity of heat by heat exchange, and this also results in a temperature rise of discharged cooling oil. In our simulation, the average value of inlet and outlet temperatures of coolant was applied to calculate the thermal equivalent convection in coolant passage. On the contrary, the temperature field of helical passage in spindles is not uniform. This linearization may further raise the difference.

\section{Conclusions}

The temperature evaluation is the first stage to characterize the thermal performances of a spindle. Although many models have been available in assessing the spindle temperature field, a lightweight and fast (low overhead/ small footprint) forecasting is not addressed in engineering up to now. Evidently, the insufficient investigation on the effect of coolant systems on spindle temperature may partly contribute to the deviation. In order to build a simple and efficient model, this paper introduces a structural scaling factor to describe the cooling unit impact on the temperature of front / rear half of a spindle. By this, we only need to model the front or rear half of a spindle when the spindle temperature estimation is required. Obviously, this reduces the data overhead and improves the computational efficiency, and it also benefits forecasting the accuracy decay and even operation life of motorized spindles. Meanwhile, this provides the possibility for the active adjustment of spindle temperature and even thermal error.

\section{Acknowledgments}

This work was funded by the National Natural Science Foundation of China (No.51775277) and the National Science and Technology Major Project of the Ministry of Science and Technology of China (No. 2015ZX0401002).

\section{Declarations}

- Conflict of interest The authors declare no competing interests.

- Consent to participate All authors consent to participate in the author team of this submitted manuscript.

- Consent to publish The submitted manuscript is approved by all authors for publication.

- Availability of data and material Data are available.

- Authors' contributions Zheng De-xing is the main contributor to this paper. He implemented the experimental studies and next proposed the structural scaling factor to describe the role of a coolant unit in spindle temperature. This factor was also integrated into the developed thermal grid model for the front half of motorized spindle. Meanwhile, he validated the proposed structural scaling factor by comparing the simulation with test results.

Chen Weifang gave some crucial comments in improving the technical route of this work. 


\section{References}

1. Peterson W, Russell T, Sadeghi F, et al. (2020) A CFD investigation of lubricant flow in deep groove ball bearings. Tribol Int. https://doi.org/10.1016/j.triboint. 2020.106735.

2. Liu JL, Ma C, Wang SL, et al. (2019) Thermal-structure interaction characteristics of a highspeed spindle-bearing system. Int J Mach Tool Manu 137:509-514.

3. Cao HG, Niu LK, Xi ST, et al. (2018) Mechanical model development of rolling bearing-rotor systems: A review. Mech Syst Signal Pr 102:37-58.

4. Oktaviana L, Van-Canh T, Hong SW (2019) Skidding analysis of angular contact ball bearing subjected to radial load and angular misalignmen. J Mech Sci Technol 33:837-845.

5. Zheng DX, Chen WF, Zheng DT (2021) An enhanced estimation on heat generation of angular contact ball bearings with vibration effect. Int J Therm Sci 159: 1-13.

6. Niel D, Changenet C, Ville F (2019) Thermomecanical study of high speed rolling element bearing: A simplified approach. P I Mech Eng J-J Eng 233:541-552.

7. Zhang P, Chen XA (2016) Thermal-mechanical coupling model-based dynamical properties analysis of a motorized spindle system. P I Mech Eng B-J Eng 230:732-743.

8. Zhang LX, Li JP, Wu YH, et al. (2018) Prediction model and experimental validation for the thermal deformation of motorized spindle. Heat Mass Transfer 54:2691-2704.

9. Meng Q, Yan X, Sun C, et al. (2020) Research on thermal resistance network modeling of motorized spindle based on the influence of various fractal parameters. Int Commun Heat Mass 117:1-14.

10. Denkena B, Bergmann B, Klemme H (2020) Cooling of motor spindles - a review. Int J Adv Manuf Techol 110:3273-3294.

11. Michael F, Markus H, Francois C, et al. (2012) Active outer ring cooling of high-loaded and high-speed ball bearings. J Eng Gas Turb Power. https:// doi.org/10.1115/GT2012-68138.

12. Sun YL, Zhang SW (2020) Experimental and numerical investigation on a novel heat pipe based cooling strategy for permanent magnet synchronous motors. Appl Therm Eng 170:114970.

13. He Q, Shen Y, Ren FZ, et al. (2017) Numerical simulation and experimental study of the air-cooled motorized spindle. P I Mech Eng C-J Mec 31:2357-2369.

14. Biesack WL, Loomis DW (1971) Electric high-speed spindle with cooling means, U.S. Patent, No.3567975.

15. Narashino SA, Kaisha SSK (1979) Lubricating and cooling system for spindle bearing assembly: U.S. Patent, No. 4137997.

16. Xia $\mathrm{CH}, \mathrm{Fu} \mathrm{JH}$, Lai JT, et al. (2015) Conjugate heat transfer in fractal tree-like channels network heat sink for high-speed motorized spindle cooling. Appl Therm Eng 90:1032-1042.

17. Kang Y, Shi X, Gao J, et al. (2017) Thermal behavior analysis of a motorized spindle with novel shaft core cooling. J Xian Jiaotong Univ 51:13-18.

18. Liu T, Zhou L, Gao WG (2021) Thermal simulation speculation-based active coolant control onto spindle bearings. Int J Adv Manuf Technol 113:337-350.

19. Grama SN., Mathur A., Badhe AN (2018) A model-based cooling strategy for motorized spindle to reduce thermal errors. Int J Mach Tool Manu 132:3-16.

20. Mori K, Bergmann B, Kono D, et al. (2019) Energy efficiency improvement of machine tool spindle cooling system with on-off control. CIRP J Manuf Sci Tec 25:14-21.

21. Chien CH, Jang JY (2018) 3-D numerical and experimental analysis of a built-in motorized high-speed spindle with helical water cooling channel. Appl Therm Eng 28:2327-2336. 
22. Zhu K, Shi XJ, Gao JM, et al. (2018) Thernal characteristics analysis fro motorized spindle with shaft core cooling based on numerical simulation and experimental research. J Xian Jiaotong Univ 52:40-47.

23. Yan K, Hong J, Zhang JH, et al. (2016) Thermal- deformation coupling in thermal network for transient analysis of spindle-bearing system. Int J Therm Sci 104:1-12.

24. Zhang X, Xu H, Chang W, et al. (2019) Torque variations of ball bearings based on dynamic model with geometrical imperfections and operating conditions. Tribol Int 133:193-205.

25. Zheng DX, Chen WF (2020) Effect of structure and assembly constraints on temperature of high-speed angular contact ball bearings with thermal network method. Mech Syst Signal Pr 145:1-18.

26. Zheng DX, Chen WF, Li MM (2018) An optimized thermal network model to estimate thermal performances on a pair of angular contact ball bearings under oil-air lubrication. Appl Therm Eng 131:328-339.

27. Muzychka Y, Yovanovitch M (2001) Thermal Resistance of Model for Non Circular Moving Heat Sourceson a Half Space. J Heat Transfer 123:624-632.

28. Xu M, Shuyun J, Ying C (2007) An improved thermal model for machine tool bearings. Int $\mathbf{J}$ Mach Tool Manu 47:53- 62.

29. Holman JP. Heat Transfer, 7th edition, New York: McGraw-Hill 1989.

30. Bjorklund IS, Kays WM (1959) Heat Transfer Between Concentric Rotating Cylinders, Trans. ASME 81:175-186.

31. Wagner C (1948) Heat Transfer from a Rotating Disk in Ambient Air. J Appl Phys 19:837-839.

32. Cobb EC, Saunders OA (1956) Heat Transfer from a Rotating Disk Proc R Soc 236:343-351.

33. Churchill SW, Chu HHS (1975) Correlation Equations for Laminar and Turbulent Free Convection from a Vertical Plate. Int J Heat Mass Tran 1975;18: 1323-1329.

34. Churchill SW, Chu HHS (1975) Correlation Equations for Laminar and Turbulent Free Convection from a Horizontal Cylinder. Int J Heat Mass Tran 1975;18: 1049-1053.

35. Li XT (2016) Calculation and design of heat exchange for motor operation, Hangzhou: Zhejiang University Press.

36. Palmgren A (2009) Ball and Roller Bearing Engineering, 3rd Ed.. USA: Burbank Philadelphia.

37. Latif MJ (2009) Heat convection. 2nd Ed. Berlin: Springer-Verlag.

38. Dittus FW, Boelter LMK (1930) Heat transfer in automobile radiators of the tubular type. Univ Calif Pubs Eng 2:443-461. 